Citation: M. Kaschny Borges, T. H. Medeiros Kamigouchi (2020) Do Youtube à escola: transformações nas práticas docentes dos professores de história, provocadas pelo acesso de estudantes a conteúdos de história veiculados por youtubers. Media Education 11(1): 37-46. doi: 10.36253/ me-9093

Received: April 2020

Accepted: May 2020

Published: July 2020

Copyright: ( 2020 M. Kaschny Borges, T. H. Medeiros Kamigouchi. This is an open access, peer-reviewed article published by Firenze University Press (http://www.fupress.com/me) and distributed under the terms of the Creative Commons Attribution License, which permits unrestricted use, distribution, and reproduction in any medium, provided the original author and source are credited.

Data Availability Statement: All relevant data are within the paper and its Supporting Information files.

Competing Interests: The Author(s) declare(s) no conflict of interest.

Pesquisa realizada com apoio da Fundação de Amparo à Pesquisa e Inovação do Estado de Santa Catarina - FAPESC.

\section{Do Youtube à escola: transformações nas práticas docentes dos professores de história, provocadas pelo acesso de estudantes a conteúdos de história veiculados por youtubers}

\author{
Youtube at school: transformations in history teachers practices \\ due to students accessing history contents by youtubers.
}

\author{
Martha Kaschny Borges, Tales Hiroshi Medeiros Kamigouchi \\ Universidade do Estado de Santa Catarina, UDESC, Brasil \\ E-mail: marthakaschny@hotmail.com; taleshmk@gmail.com
}

Resumo. Este artigo descreve transformações nas práticas docentes de professores de história do Ensino Médio, quando seus estudantes acessam conteúdos de história pela rede social digital Youtube. Fruto dos resultados de uma pesquisa de mestrado, pretende identificar e descrever quais as estratégias adotadas por professores frente ao desafio de lecionar para uma geração hiperconectada. A pesquisa foi estruturada como sendo de cunho qualitativa e teve como pressupostos teórico-metodológicos: Goodman (1961) para a técnica de pesquisa Snowball (bola de neve); Bardin (2004) para a análise do conteúdo das entrevistas; além do diálogo com os autores Bruno Latour (2012); André Lemos (2008); Martha K. Borges (2007); Pierre Lévy (2010); Lucia Santaella e Renata Lemos (2010); Maria Auxiliadora Schmidt e Marlene Cainelli (2004); e Maria Mizukami (1986). As evidências corroboram com a compreensão de que o processo de ensino-aprendizagem no tempo da cibercultura e do ciberespaço demandam novas iniciativas e abordagens que ultrapassem o modelo tradicional de ensino, como por exemplo, dedicar tempo de planejamento na observação e análise de canais de Youtube que divulgam conceitos distorcidos.

Palavras chave:Cibercultura e Educação, Teoria Ator-Rede, Youtube, Ensino de História, Práticas docentes. 
Mizukami (1986). The evidence corroborates with the understanding that the teaching-learning process in the time of cyberculture and cyberspace demand new initiatives and approaches that go beyond the traditional teaching model, such as, for example, dedicating planning time in the observation and analysis of YouTube channels that disseminate distorted concepts.

Keywords: cyberculture and education, Theory Actor-Network, Youtube, history teaching, teaching practices.

\section{INTRODUÇÃO}

O Youtube é uma plataforma especializada no compartilhamento de vídeos na internet, a qual é utilizada para muitas finalidades, dentre elas: entretenimento; promoção pessoal; divulgação de conteúdo amador e profissional; e até mesmo, para fins lucrativos por meio da monetização'. Em outras palavras, "cada um desses participantes chega ao Youtube com seus propósitos e objetivos e o modelam coletivamente como um sistema cultural dinâmico: o Youtube é um site de cultura participativa" (Burgess \& Green, 2009, p. 14). Dentre a imensa pluralidade de vídeos produzidos e compartilhados por essa plataforma, encontram-se também produções que abordam conteúdos previstos pelos parâmetros curriculares das escolas. Muitos são produzidos e compartilhados, inclusive, por professores e/ou ex-professores de escolas em busca de visibilidade, retorno financeiro com a monetização, ou até mesmo, pela simples iniciativa de poder colaborar com outros usuários da plataforma ${ }^{2}$.

Há também outros produtores de conteúdo cujo foco dos vídeos compartilhados são temas do momento, presentes nos compartilhamentos online das redes sociais. Os vídeos, muitas vezes, são elaborados de maneira simples, sem grandes produções gráficas, a partir de webcams; e não raramente trazem uma pessoa comentando um tema sobre seu próprio ponto de vista. O descentralismo oportunizado pela interatividade da Web $2.0^{3}$,

\footnotetext{
${ }^{1}$ Monetização significa aproveitar algo para ganhar dinheiro, ou melhor, obter lucro. Muitos sites têm utilizado a monetização como fonte de captação de dinheiro, uma vez que divulgam algo de interesse público, cujo número de visualizações do site se converte em valor financeiro pago por propagandas comerciais.

${ }^{2}$ Um exemplo desta situação é o canal hospedado no Youtube chamado Biologia Total com Prof. Jubilut. O professor passou a disponibilizar vídeos na plataforma abordando conteúdos da disciplina Biologia, e em pouco tempo alcançou um grande número de acessos e inscrições em seu canal. Hoje já soma milhares de assinaturas em seu canal, o que o levou a se tornar conhecido nacionalmente, dando entrevistas em rádios, jornais, revistas e televisão. Para maiores informações, acesse: Biologia Total com Prof. Jubilut (2006, Sep 19). Retrieved May 1, 2020, from Youtube: https://www.youtube.com/user/jubilut/about.

${ }^{3} \mathrm{Da}$ mesma maneira que outras tecnologias, a internet obedece a uma premissa evolutiva, e as principais etapas evolutivas são: Web 1.0, Web 2.0 e Web 3.0 (Farah, 2012). A Web 1.0 é conhecida como a primeira geração da internet. Por meio dela, usuários acessam informações por meio de navegadores (browsers), mas não podiam interagir (Farah,
}

parece ser um ingrediente importante dessa nova relação de poder legitimada pela dinâmica própria das redes sociais, ou, como aponta Primo, "nestes casos importa menos a formação especializada de membros individuais. A credibilidade e relevância dos materiais publicados é reconhecida a partir da constante dinâmica de construção e atualização coletiva (Primo, 2007, p. 6).

Quando os temas comentados e compartilhados por youtubers ${ }^{4}$ tratam de conteúdos previstos nos livros didáticos de História, necessariamente ocorrem desdobramentos em sala de aula. Se majoritariamente os profissionais da educação estiveram submetidos ao ensino institucional que os comprometeram a exercer a docência nos pilares da ética e da moral, os novos formadores de opinião na Internet não necessariamente estão alinhados aos mesmos princípios. Como bem alertam as historiadoras Schmidt e Cainelli quanto à função do professor de História, “apesar de não se poder modificar o passado, ao interpretá-lo e narrá-lo à luz das lutas individuais e coletivas, pode-se levantar questões sobre o presente e pensar o futuro a partir dos princípios da liberdade, democracia e cidadania" (Schmidt \& Cainelli, 2004, p. 70).

Como defendem as autoras Andrea Lapa, Isabel Coelho e Simone Schwertl, a comunicação propiciada pelas redes sociais se constitui enquanto espaço público educador, ou, melhor dizendo: "no mundo contemporâneo, um espaço público que merece destaque são as redes sociais, que devem ser estudadas no seu potencial de serem (ou se tornarem) esferas públicas, portan-

2012). Já a geração subsequente, a Web 2.0, possui como principal característica a interatividade. Nela, usuários podem interagir uns com os outros, comentar, criar e compartilhar conteúdo (Farah, 2012). Atualmente, está se expandindo a geração Web. 3.0, que segundo Paletta e Mucheroni (2015), "é a Web construída por mecanismos semânticos de organização do conhecimento" (p. 3). Em outras palavras, esta nova geração oferece personalização das informações aos usuários e buscas inteligentes. Em uma realidade não tão distante já é aguardada a emergência da geração Web 4.0, que seria uma Web auto-organizada por mecanismos de inteligência artificial, na qual a conexão máquina-máquina traria mais agilidade nas buscas e na organização do conhecimento, de acordo com a necessidade humana (Paletta \& Mucheroni, 2015).

${ }^{4}$ Este termo tem se popularizado cada vez mais para designar as pessoas que mantêm canais de compartilhamento periódico no Youtube e, consequentemente, muitos seguidores. Não foi encontrado ainda alguma menção ao termo youtuber nos autores que fundamentam este projeto de pesquisa. 
to, espaços de possibilidade para a formação do sujeito" (Lapa et al., 2015, p. 8). As redes sociais são espaços constituídos por múltiplos aspectos que contribuem para a formação dos sujeitos, uma vez que neles as pessoas constituem voz ativa ao mesmo passo em que também são ouvintes; se representam e dialogam em condições de igualdade (Lapa et al., 2015). Com as redes sociais desempenhando um papel de espaço público educador, e buscando uma aproximação com a $\operatorname{TAR}^{5}$ e o entendimento que circunda a concepção de controvérsia ${ }^{6}$, configurou-se a questão central desta pesquisa.

A indagação se esboçou na seguinte forma: que controvérsias emergem nas práticas docentes de professores de história, provocadas pelo acesso de educandos do ensino médio aos conteúdos especializados em história, veiculados por youtubers? O objetivo geral da nossa pesquisa foi analisar as práticas docentes de professores de história, provocadas pelo acesso de educandos do ensino médio aos conteúdos especializados em história, veiculados por youtubers.

Para chegarmos ao objetivo proposto, optamos por uma pesquisa qualitativa. A ferramenta de coleta de dados adotada foi a realização de entrevistas com professores de história no ensino médio. Devido à procura de múltiplas narrativas que pudessem evidenciar reflexos da cibercultura e das redes sociais nas práticas docentes de professores de história, optamos pela técnica de pesquisa chamada Snowball (Goodman, 1961). Esta técnica produz amostragem em ondas de indicações entre sujeitos que reservam as mesmas características procuradas pela pesquisa. Isto é, partindo de uma semente, no caso, um professor de história cujas práticas evidenciem diálogo com aspectos da cibercultura, indicou outro professor com as mesmas características, e este, indicou outro, assim sucessivamente até parar a geração de ondas. Duas sementes geradoras de ondas foram adotadas conside-

\footnotetext{
${ }^{5}$ TAR é a abreviação de Teoria Ator-Rede, conforme consta na lista de abreviaturas e siglas. Para se ter um entendimento prévio do conceito que será detalhadamente descrito na próxima seção, a TAR é um conjunto de conceitos e pressupostos teóricos que busca descrever a "formação das associações, dos movimentos de conexão e desconexão, da comunicação e da não-comunicação das coisas que se estabelecem sempre por três condições móveis de instauração espaço-temporais: 1. Não sabemos exatamente a fonte original da ação; 2 . Não sabemos exatamente a direção do vetor da ação e; 3 . O valor e a qualidade da associação estão sempre a se construir" (Lemos, 2013, p. 32). Também conhecida como "sociologia da mobilidade" (Lemos, 2013, p. 31), a TAR propõe a observação do movimento dos atores - sejam eles humanos e não-humanos - nos fenômenos, que quando em evidência, também chamados de controvérsias.

${ }^{6}$ As controvérsias ocorrem, segundo a TAR, nos momentos de desestabilização, quando problemas são colocados em evidência e são geradas novas mediações. Isto é, controvérsias só são geradas quando as conexões e as disputas são evidenciadas, caso contrário, não há movimento e o social encontra-se estabilizado (Lemos, 2013).
}

rando-se duas realidades profissionais distintas: professores atuantes no ensino público e professores atuantes no ensino privado.

Foram entrevistados doze professores de história, e para a análise dos dados obtidos por meio das entrevistas, valemo-nos da técnica de análise de conteúdo proposta pela professora de Psicologia na Universidade de Paris V, Laurence Bardin (2004). Enquanto método, a proposição de Bardin (2004) articula um

[ ]conjunto de técnicas de análise das comunicações visando a obter, por procedimentos sistemáticos e objetivos de descrição do conteúdo das mensagens, indicadores (quantitativos ou não) que permitam a inferência de conhecimentos relativos às condições de produção/ recepção (variáveis inferidas) dessas mensagens (Bardin, 2004, p. 37).

Ressalta-se que esta pesquisa é um subprojeto vinculado a outro mais amplo desenvolvido pelo grupo de pesquisa "Educação e Cibercultura". O projeto é intitulado "Educação e cibercultura: o entre lugar das políticas, das práticas educativas, das tecnologias digitais e dos actantes das redes sociotécnicas", coordenado pela Profa Dra. Martha Kaschny Borges. A aprovação pelo Comitê de Ética em Pesquisas Envolvendo Seres Humanos da UDESC $^{8}$ deu-se em outubro de 2017 por meio do parecer número 2.313.10.

\section{PRÁTICAS DOCENTES SE TRANSFORMAM}

Uma vez perguntei para os alunos: quando você está doente, você procura quem? Um médico, responderam. [...] Por acaso você permitiria que eu fizesse a sua casa? Ah, claro que não, professor. Eu perguntei: por que que quando vocês querem aprender alguma coisa de filosofia, sociologia, história ou geografia vocês correm pro Youtube? Aí um aluno respondeu: ah, mas o youtuber lê e pode comentar sobre o livro". Eu falei: claro, ele pode comentar sobre o livro, opinião é livre, mas trabalhar enquanto ciência, não. Eu não posso elevar a opinião ao nível de conhecimento científico,

\footnotetext{
${ }^{7}$ Formado em 2005, o grupo de Pesquisa "Educação e Cibercultura" é coordenado pela Profa. Dra. Martha Kaschny Borges, e vinculado à linha de pesquisa Educação, Comunicação e Tecnologia do Programa de Pós-Graduação da UDESC. Espelho do grupo no site do Conselho Nacional de Desenvolvimento Científico e Tecnológico (CNPq). (2014, March 7) .Retrieved May 1, 2020, from CNPQ: http://dgp.cnpq.br/dgp/ espelhogrupo/0500088587763773.

${ }^{8}$ O Comitê de Ética em Pesquisas Envolvendo Seres Humanos da Universidade do Estado de Santa Catarina - CEPSH/UDESC, é um órgão vinculado diretamente ao Gabinete do Reitor, e devidamente credenciado pela Comissão Nacional de Ética em Pesquisa - CONEP, em conformidade à Resolução 466/2012/CNS/MS. Para maiores informações, consultar Comitê de Ética e Pesquisa com Seres Humanos. Retrieved May 1, 2020, from UDESC: https://www.udesc.br/comitedeeticaepesquisacomsereshumanos.
} 
isso é criminoso, é um estelionato intelectual, porque você promete entregar uma informação enquanto o que você está entregando são falácias [...] (Caio).

A reflexão de Caio serve à esta provocação inicial que pretende evidenciar relatos que dizem respeito quanto: à importância de distinguir opinião de conhecimento científico; à valorização cotidiana do pensamento crítico científico; e às possibilidades de professores preparem seus educandos para a aprendizagem imersiva com autonomia. Frente aos desafios de ensinar história a uma geração acostumada a interagir com inúmeras informações diariamente, algumas práticas dos professores são desafiadas. Para Lévy,

As novas possibilidades de criação coletiva distribuída, aprendizagem cooperativa e colaboração em rede oferecidas pelo ciberespaço colocam novamente em questão o funcionamento das instituições e os modos habituais de divisão do trabalho, tanto nas empresas como nas escolas. Como manter as práticas pedagógicas atualizadas com esses novos processos de transação de conhecimento? (Lévy, 2010, p. 174).

Em muitos dos temas em disputa pela narrativa histórica, professores são encarados por questionamentos e posturas que em boa parte do tempo buscam o confronto direto, às vezes pelo tom de voz do estudante, outras, marcadas por expressões de desprezo ou deboche, tensionando as práticas pedagógicas tradicionais. Novas práticas pedagógicas são demandadas no próprio contexto da cibercultura, mas tornam-se imprescindíveis diante de um cenário de veiculação de conhecimento conspiratório ou distorcido sobre a história curricular. Neste ambiente de controvérsias emergentes, alguns professores entrevistados deixam rastros sobre suas escolhas dentro deste contexto que exige atualização imediata. Isto é, ao serem questionados quanto à adoção de novas práticas pedagógicas, inevitavelmente as respostas se delinearam pelo seguinte caminho: o estudo teórico e a retomada de conceitos e informações para desconstruir falseamentos; e a valorização do conhecimento histórico produzido de maneira científica.

Professor Eduardo, por exemplo, apesar de reconhecer que possui conhecimento básico de alguns youtubers que produzem discursos sobre a história de maneira distorcida e também de poucos que produzem conteúdo com olhar científico, mantém um aparente distanciamento da possibilidade de dar indicações a seus estudantes na plataforma. Muito provavelmente isso deva-se a seu perfil, de certo modo, ligado ao estilo tradicional de ensino 9 , estruturado na figura do professor como

\footnotetext{
${ }^{9}$ A ênfase é dada às situações de sala de aula, onde os alunos são "ins-
} truídos" e "ensinados" pelo professor. Comumente, pois, subordina-se a autoridade no conhecimento, pautado pelo diálogo com o conteúdo que é trabalhado em sala de aula a partir da sua mediação. Já o planejamento de aula de Eduardo prevê uma preparação prévia, um estudo bibliográfico antevendo-se a falseamentos que possam aparecer. Eduardo diz que:

Essa situação faz a gente buscar uma preparação, a gente não pode estar despreparado, tem que ter um embasamento sólido. Tive que resgatar alguns dados, algumas fontes pra ter uma base, um amparo bibliográfico para contestar aquilo que muitos não aceitam. A informação, a análise, ela precisa ser sempre sedimentada com argumentos sólidos, então é necessário a gente sempre estar preparado e sempre buscar novas informações, novas formas de enxergar aquela situação. Então não podemos ficar dogmáticos, né. A nossa situação de professor nos leva a ser mais pragmáticos do que dogmáticos. Temos que nos adaptar a essas situações. [...] A nossa vida de professor é sempre um constante estudo, a gente não pode parar de estudar. Em nenhuma área, né, ainda mais na área de história. Então, apesar de muitos acharem que o passado já está pronto e acabado, não é assim que nós historiadores vemos o passado. Porque isso que a gente tem sempre que se renovar, estar sempre aprendendo (Eduardo).

Eduardo ressalta uma característica intrínseca da profissão do professor, isto é, a necessidade de estudo contínuo e de renovação do saber. Ainda assim, não deixa de frisar, por exemplo, que, sobre o cenário atual em que eventualmente estudantes apresentam argumentos distorcidos que evidenciam a disputa narrativa sobre o conteúdo, é necessário buscar a história acadêmica para rever informações e confirmar conceitos. Se a produção de conhecimento não se enquadra delimitada em casas oficiais do saber, sobretudo na era da cibercultura, é necessário que o professor assuma o papel de mediador do conhecimento confiável e force a controvérsia aberta a se estabilizar em torno do conhecimento histórico científico. O professor como mediador, amparado na experiência em sala de aula e em princípios teóricos e éticos, desenvolve suas próprias estratégias e age em relação ao estudante. Explica conceitos apropriados do conhecimento científico, traduz e faz a mediação ao estudante que questiona. Nesta mobilidade estabelecida entre os actantes professor e estudantes, o professor mediador busca a estabilização da controvérsia por meio da sua mediação de conceitos (Lemos, 2013).

É neste espaço aberto da controvérsia em torno de alguns conteúdos em disputa que se faz necessário que o professor difunda o conhecimento originado da pes-

educação à instrução, considerando a aprendizagem do aluno como um fim em si mesmo: os conteúdos e as informações têm de ser adquiridos, os modelos imitados (Mizukami, 1986, p. 13). 
quisa científica, que atue mediando termos e saberes, e sobretudo, aproveite a oposição de narrativas como um espaço valioso de construção do conhecimento crítico. Neste contexto de verbalização, Eduardo destaca sobre a importância de o professor exercer um papel objetivo na valorização do conhecimento científico e não se tornar sentencioso na sua argumentação. O professor deve, sobretudo, ensinar a raciocinar.

[...] o professor de história ajuda o aluno a adquirir as ferramentas de trabalho necessárias para aprender a pensar historicamente, o saber-fazer, o saber-fazer-bem, lançando os germes do histórico. Ele é o responsável por ensinar ao aluno como captar e valorizar a diversidade das fontes e dos pontos de vista históricos, levando-o a reconstruir, por adução, o percurso da narrativa histórica. Ao professor cabe ensinar ao aluno como levantar problemas, procurando transformar, em cada aula de história, temas e problemáticas em narrativas históricas. Ensinar História passar a ser, então, dar condições ao aluno para poder participar do processo de fazer o conhecimento histórico, de construí-lo (Schmidt \& Cainelli, 2004, p. 30).

Na esteira do trecho supracitado de Schmidt e Cainelli e corroborando com o depoimento de Eduardo, é necessário que o estudante veja o conhecimento sobre o passado como algo inacabado e em constante construção, isto é, o próprio estudante faz parte do estágio de construção do conhecimento histórico e, portanto, compõe o cenário de concorrências do discurso histórico e nele também empreende. Assim sendo, problematizar visões distorcidas originárias de plataformas como o Youtube, pode desempenhar um potencial dentro da análise de diversas fontes do conhecimento, como apontado por Schmidt e Cainelli.

As entrevistas também revelaram que as controvérsias estão suscetíveis a aflorarem caso o tema esteja circulando pelas redes sociais. No caso do professor Bernardo, o estudo de argumentos durante um planejamento é uma prática desenvolvida, mas segundo ele, isto depende muito do tema trabalhado, pois muitos assuntos do conteúdo curricular de história não permitirão controvérsias originadas das narrativas de youtubers.

[...] Eu chego a pensar estratégias para caso apareça esse debate, eu tenho armas pra combater o discurso mais simplista desse aluno. Acho que sim, tem que se preparar um pouquinho mais, mas que nem eu te falei, também não pode ficar uma bola de neve e tu não sair desse conteúdo, né. Tenho que planejar um pouquinho mais, até porque eu sei que se eu falar de Egito Antigo não é a mesma coisa do que eu falar de Ditadura Militar. Tu não podes encarar como a mesma coisa (Bernardo).

Bernardo narra uma situação em torno do contexto da controvérsia, onde existem temas que geram debate, e outros que seguem pautados pelo conteúdo do livro didático e as explicações do professor, sem maiores contratempos. Nas situações em que existem controvérsias quanto ao conteúdo, opta por uma abordagem dialogada (Schmidt \& Cainelli, 2004), mas reconhece os limites desta prática, uma vez que se persistir no excessivo diálogo com os estudantes, acaba incorrendo em um problema que assola a realidade docente: o não cumprimento do conteúdo da apostila.

Num tipo de abordagem muito próxima a de Bernardo, Caio também opta por desenvolver a abordagem dialogada, plantando as interrogações que julga necessário para conduzir a linha de raciocínio:

Eu não bato de frente com estudante de modo algum, é tudo no respeito. Eu uso aquela coisa meio método socrático, fazendo perguntas. Eu faço perguntas deixo que ele conclua as coisas, pra que ele próprio perceba se o argumento dele tem sustentação ou não. Eu tenho que tentar tirar ele do senso comum e aproximá-lo do conhecimento científico (Caio).

A aproximação do conhecimento científico é realizada por meio de "questões individuais ou coletivas" (Schmidt \& Cainelli, 2004, p. 33), desempenhando um protagonismo do estudante na procura pelas respostas, fornecendo a impressão de que a classe participa diretamente da construção de seu próprio saber (Schmidt \& Cainelli, 2004). Caio afirma que suas perguntas são objetivas, que estimulam a reflexão e que buscam conduzir o estudante à problematização do conhecimento prévio que ele possui sobre um determinado assunto. As provocações primeiramente desconstroem para depois construírem outro saber então edificado na narrativa que o professor apresenta, dialogando com o conhecimento científico. Há nesta ação aquilo que Mizukami (1986) chama por "abordagem cognitivista", ou melhor, a prática docente consiste em criar as condições para que o estudante aprenda a aprender. Por meio de seus questionamentos que inevitavelmente conduzem o estudante às contradições dos argumentos, Caio desenvolve uma didática que atribui o protagonismo ao estudante, ou seja, durante este "tipo de atividade intelectual que serão formadas as novas noções e operações” (Mizukami, 1986, p. 80). Neste sentido, a ação do educando em busca das respostas às perguntas lançadas pelo professor constitui o centro do processo formativo e a condição de desenvolvimento do conhecimento (Mizukami, 1986). Os questionamentos do professor embasados nos argumentos apresentados pelo estudante, quando lançados por Caio, não só geram a condição para o desenvolvimento individual como também de todo o grupo, pois, a sala de aula também é um espaço coletivo onde os colegas cooperam com pon- 
derações e pontos de vista sobre o que se está sendo discutido.

No âmbito das controvérsias em temas da história, a opção dos professores em dialogar com os estudantes faz parte de uma estratégia não somente didática, mas resulta de uma escolha ética como resposta ao ambiente de perseguição ideológica. Ambiente este que traça orientações muito claras, nos canais do Youtube, sobre como desestabilizar a aula e como desafiar a autoridade do professor. Os professores revelam que, ao perceberem a hostilidade, muitas vezes são tentados a dar respostas que podem colocar o estudante em situação vexatória, e em alguns casos até ocorre, mas que a reação ideal é desconstruir as falácias por meio do diálogo, utilizando o raciocínio do próprio educando para a desconstrução de visões equivocadas sobre o assunto.

Professor Bruno, por exemplo, conta que certa vez, após uma aula inaugural, a qual fez questão de criticar abertamente teorias conspiratórias e distorções historiográficas propagadas por alguns youtubers, ao final da aula uma estudante o chamou para conversar. Durante o diálogo, Bruno foi questionado por ela sobre o porquê de ele estar falando a respeito de assuntos "polêmicos", ou usando argumentos que "pareciam ser de esquerda", "coisas do comunismo". Segundo relata Bruno, questionamentos desta natureza são recorrentes, e qualquer argumento do professor contendo críticas ao sistema econômico ou à desigualdade social brasileira - um posicionamento relativamente corriqueiro aos professores das ciências humanas -, são taxados de "comunistas" ou "esquerdistas", tanto por alguns estudantes quanto por seus pais. Bruno descreve suas práticas:

Tu tens que pegar o que tu tiver de ferramentas dentro da tua ciência pra aproximação da realidade. Daí eu falo da Revolução Francesa, jacobinos que se sentavam do lado esquerdo, que a esquerda teve experiencias ruins, como o período do terror, mas enfim, que criou-se filosoficamente a esquerda enquanto uma visão de defesa das pessoas pobres. [...] Aí à medida em que fui mostrando, aí a aluna agradeceu. [...] É pra isso que serve a educação! Na minha profissão de professor de história a minha missão [...] é tentar deixar ela mais científica, mais racional e com um futuro mais próspero (Bruno).

Novamente a prática estabelece um diálogo com as concepções da estudante para, na sequência, aproximá-la do conhecimento científico. Há nesta opção uma predileção pela retomada de conceitos históricos: prática alinhada com a "transposição didática dos conteúdos"10 (Schmidt \& Cainelli, 2004, p. 31).

\footnotetext{
10 "A transposição didática é [...] um processo de transformação científica, didática até sua tradução no campo escolar. Ela permite pensar a transformação de um saber científico e social que afeta os objetos de
}

Aprender conceitos históricos é construir uma grade de referência que auxilie o aluno em sua interpretação e compreensão da realidade social, facilitando a leitura do mundo em que vive. Ensinar conceitos históricos não é impor o uso abusivo de termos técnicos e definições abstratas nem de memorização de palavras e de seu significado (Schmidt \& Cainelli, 2004, p. 63).

Isto é, por meio de uma abordagem dialogada, professor Bruno constrói conceitos que permitem diferenciar direita e esquerda, retomando o processo revolucionário francês ocorrido nos últimos anos do século XVIII. A reação da estudante ao final da aproximação com os conceitos históricos deixa Bruno satisfeito no seu exercício como professor, uma vez que ela se emociona ao final e reconhece ter manifestado conhecimentos prévios carregados de preconceitos. Frente aos conceitos históricos apresentados por Bruno, as controvérsias naquela situação se resolveram, ou pelo menos se harmonizaram.

É reconhecido por professores que muitos assuntos com controvérsias são prontamente apaziguados. Arthur diz que

[...] quando eles batem de frente com o conhecimento pautado em postulados científicos, aquilo incomoda um pouco. Porque eles sabem que aquilo que está sendo falado ali, por mais que eles queiram discordar, eles sabem que aquilo tem uma autoridade. Pô, é um argumento que está baseado, tem as características que o professor apresentou e isso incomoda um pouco [...] Então você consegue desconstruir essas coisas, só que tem que ter um pouco de paciência (Arthur).

Os relatos evidenciam que, diante de uma explicação do professor com embasamento científico e esclarecimento de conceitos históricos, normalmente as controvérsias agem à favor do ambiente de discussão do tema, estabilizando-se ao final e dando continuidade à aula. Para alguns dos professores entrevistados, a interação ativa de estudantes com questionamentos chama a atenção dos colegas, quebra com o caráter meramente expositivo, estimula o raciocínio e a interpretação coletiva do tema. Neste ambiente em que o estudante está inserido é o que Mizukami (1986) diz que ele necessita ser desafiador, pois, “a motivação é caracterizada por desequilíbrio, necessidade, carência, contradição, desorganização etc. Um ambiente de tal tipo será favorável à motivação

conhecimento em um saber a ensinar, tal qual aparece nos programas, manuais, na palavra do professor, considerados não somente científicos [...] Isso significa, então, um verdadeiro processo de criação e não somente de simplificação, redução. [...]" (INRP, 1989, p. 14, como citado em Schmidt \& Cainelli, 2004, p. 31). 
intrínseca do aluno" (Mizukami, 1986, p. 80). As verbalizações dos professores endossam a contradição como fator motivador, onde na agitação promovida por perguntas, respostas, análises, contradições e até mesmo as pausas para o pensar formam um ingrediente captador de atenção. As operações mentais individuais seguindo o raciocínio do professor constroem uma espécie de clima construtivo que entusiasma e se alastra para os demais da sala.

Cabe ainda análise sobre a verbalização de Arthur quanto à legitimidade ao que o professor dialoga com o estudante. $\mathrm{Na}$ mediação como um ato possuidor do objetivo de transformar o outro actante ao mesmo tempo em que também é transformado, Arthur empreende ação pela circulação de ideias. O professor no papel de mediador age colocando conhecimento histórico acadêmico em movimento. Traz como instrumento à sua prática docente ideias concebidas no contexto científico, e impacta as concepções prévias dos estudantes. Como mediador Arthur valoriza a consistência do conhecimento científico frente à fragilidade dos argumentos geradores de contestação.

Embora os estudantes sejam leitores no seu tempo histórico, ou seja, pessoas dotadas de processos cognitivos potencializados pelo surgimento das TD, nota-se por estes relatos que o papel do professor como mediador não é substituído pela novidade técnica. Como bem descreve Santaella (2013)

\section{[...] é preciso considerar que o surgimento histórico de um novo tipo de leitor com os processos cognitivos que ele traz não leva os anteriores ao desaparecimento. Cada um deles aciona habilidades cognitivas específicas de modo que um não pode substituir o outro. Cada um deles contribui de modo diferencial para a formação de um leitor provido de habilidades cognitivas cada vez mais híbridas e cada vez mais ricas (Santaella, 2013, p. 26).}

Neste sentido, a incorporação das tecnologias e das redes sociais à educação não substitui a figura do professor como mediador, muito pelo contrário, revela a emergência de que novas estratégias integrem os quatro tipos de leitores: "contemplativo, movente, imersivo e ubíquo" (Santaella, 2013, p. 26), isto é, há de se ter formas "de complementação e não de substituição de um leitor pelo outro" (Santaella, 2013, p. 26).

Outra questão importante que surgiu nas entrevistas e que busca um olhar de compreensão, trata sobre o desafio de desenvolver nos estudantes o senso de crítico para a seleção de conteúdos. Sabe-se que as dificuldades na seleção crítica de conteúdos e no aprofundamento de conhecimentos necessários à formação, despontam justamente pela condição do sujeito imersivo: "multifun- cional, multilinear e multimídia" (Borges \& Oliveira, 2016, p. 437). Neste sentido, o relato de Dante traz à tona uma situação emblemática sobre a dificuldade de uma estudante em aprofundar uma resposta em uma questão de prova com base em uma vídeo-aula assistida no Youtube. Segundo Dante, uma das questões da prova de história do terceiro ano do ensino médio solicitava uma explicação conceitual sobre etnocentrismo. Após a correção e devolutiva da prova, uma estudante solicitou revisão da nota, pois havia respondido a questão com base nos argumentos que vira em uma vídeo-aula. Dante, por sua vez, considerou a resposta da estudante incompleta, pois a explicação em sala de aula ultrapassava os termos abordados pela vídeo-aula, e assim, fez valer como critério de avaliação a sua explicação em sala de aula.

Então o que posso dizer é o seguinte, aqui em sala de aula eu te apontei aspectos desse conceito que uma vídeo-aula de 20 minutos pode não ter apontado." Ela disse "é verdade, ele não falou disso lá”. Mas eu observei que ele é professor de uma rede conceituada, e se essa rede de ensino é conceituada, provavelmente o conteúdo que ele veicula ali passe por alguma supervisão, então aqueles 20 minutos de vídeo-aula, falam apenas o que interessa. Ou seja, ela tinha uma confiança grande na rede privada que oferecia esse ensino e, sobretudo, na seleção do que essa rede privada fazia pra aparecer na vídeo-aula. Eu falei "bom, nem sempre é assim" (Dante).

Percebe-se que a estudante depositou confiança no conteúdo da vídeo-aula, sobretudo, por se tratar de uma aula divulgada no Youtube por uma rede conceituada de educação, da rede privada de ensino. Para pacificar a controvérsia, Dante propôs uma explicação na aula seguinte no intuito de mostrar a complexidade e amplitude de certos conceitos e que, portanto, fazia-se necessário estar atento, principalmente, à explicação dada em sala de aula, pois, muitas vezes, vídeo-aulas no Youtube podem assumir outras abordagens e diferentes recortes teóricos. Assim sendo Dante descreve:

Eu passei o final de semana levantando coisas sobre isso, algumas coisas eu já tinha lido na universidade ou por conta própria e tal, juntei dicionário de filosofia, revisões bibliográficas, juntei bastante coisa. [...] Então levei pra ela.[...]. E então conversamos bastante nessa aula sobre isso, e ai ela viu o tamanho do problema. Talvez ela teve uma dimensão, ela ficou até meio horrorizada com o fato de que aquilo que a gente discutiu tenha sido tão básico, e o fato de que ela deveria ter se atido pra avaliação fosse tão básico. Então, essa foi a minha forma de ensinar a ela como funciona a disciplina de história na rede básica, e inclusive pra turma, que há um mundo muito maior lá fora e que tudo que a gente discute, não é por que eu cobro em uma prova e assim por diante, que um curso da educa- 
ção básica que eles vão atingir isso. É preciso ter calma [...] (Dante).

Situações como a exposta por Dante se enquadram nos desafios da escola em conviver com a sociedade digital. Sua prática buscou dar um panorama à turma sobre a abrangência de temas nas ciências humanas e que, portanto, a aprendizagem imersiva, embora necessária e extremamente importante, deve respeitar alguns cuidados. Em outras palavras, Dante fez evidenciar a complexidade do conhecimento científico e valorizar o seu papel em sala de aula como mediador de uma parte desta área do conhecimento. É apreciável a autonomia desenvolvida pela estudante e, embora tenha buscado uma fonte de informação muito utilizada por sua geração durante os estudos, a voz do professor como mediador de conhecimento ainda não pode ser completamente substituída pelas TD (Santaella, 2013).

A descrição das práticas até este ponto da pesquisa tentou organizar algumas ações desenvolvidas pelos professores entrevistados. As evidências corroboram com a compreensão de que o processo de ensino-aprendizagem no tempo da cibercultura e do ciberespaço demandam novas iniciativas e abordagens que ultrapassem o modelo tradicional de ensino.

Verbalizações mostraram professores dedicando tempo do planejamento para a busca de dados científicos, para a atualização de informações, e até mesmo, para a observação e análise de canais de Youtube que divulgam conceitos distorcidos. Para alguns professores entrevistados, é de suma importância compreender as ideias e a forma de interpretar temas históricos de youtubers que veiculam distorções. Além disso, professores narraram utilizar o conhecimento trazido pelos estudantes, embora distorcido e enviesado, como ponto de partida para a construção do diálogo. Isto é, estes professores assumem o papel mediador do conhecimento científico e também constroem com os estudantes o entendimento de que o conhecimento histórico configura-se como algo em movimento e em permanente construção. Dentro deste contexto, diferentes fontes narrativas de conhecimento histórico concorrem em uma dinâmica de procura pela estabilização e aceitação, e que, portanto, toda fonte de conhecimento deve ser problematizada e criticada. Ao trazerem este olhar à tona, o conhecimento científico em movimento pela mediação do professor assume visível vantagem, uma vez que encontra-se alicerçado na metodologia científica, ou melhor, seu processo de gestação se deu por meio do debate até chegar a um consenso, mesmo que este seja momentâneo.

Outra abordagem prática que se mostrou presente em alguns relatos é realização de perguntas aos estu- dantes, ou melhor, o lançamento de questões desafio como método de mediação do conhecimento científico. Nesta prática, as perguntas feitas ao estudante guiam a reflexão - no modo individual ou coletivo - no processo de busca pelas respostas. Por meio desta prática é possível aos professores introduzirem conceitos históricos à medida em que desafiam o estudante com suas perguntas. Conscientemente o professor conduz a reflexão por um caminho de exposição das contradições, objetivando desconstruir aquele conhecimento simplista, abrindo espaço para o encontro com o conhecimento histórico científico.

Por fim, a prática narrada pela experiência de Dante e presente na essência de outros relatos tratou sobre a valorização da mediação feita pelo professor na sala de aula. Isto é, esta prática docente tem como objetivo salientar a importância dos argumentos do professor e demonstrar que as aulas não podem ser substituídas somente pela leitura imersiva de conteúdos no Youtube, por exemplo. A tradução ou mediação de conteúdo em sala de aula empreende uma série de escolhas didáticas e teóricas do professor e, portanto, ambas não devem se substituir, mas serem a melhor agregação possível de duas técnicas.

\section{CONSIDERAÇÕES FINAIS}

Novos contextos exigem outras posturas, e assim, professores têm buscado práticas diferentes e, talvez, inovadoras, para ensinar os conteúdos escolares para esta geração. Os comportamentos individuais de cada professor revelam práticas dotadas de elementos das abordagens tradicional, comportamentalista, humanista, cognitivista e sócio-cultural, que se mesclam e se complementam nas experiências diárias em sala de aula. Entretanto, nos parece que as práticas que mais predominaram nos discursos desses professores, foram práticas do tipo cognitivista, uma vez que eles estão estimulando o diálogo com o conhecimento prévio do estudante, em um movimento que tenta articular estas ideias prévias (muitas delas originadas do Youtube) com os conteúdos curriculares. Há neste estímulo à interação de diferentes interpretações uma mediação que visa auxiliar a aprendizagem, exercitando relações e combinações características da aquisição de conhecimento por meio dos estímulos do meio de vivência. Vislumbra-se então, a sala de aula como um ambiente propício à discordância, cujo objetivo é aproximar o estudante do conhecimento científico. Este modo de agir dos professores tenta enfrentar de frente o fato de que, aparentemente devido a própria lógica do algoritmo do Youtube - um 
actante não-humano age como mediador, conectando os leitores moventes a vídeos cujo a qualidade importa menos do que a quantidade de likes e de visualizações. Para este tipo de leitor, segundo Santaella (2013), o processo cognitivo requer um mundo em movimento entre o verbo, o som e a imagem. Assim, videoaulas do Youtube configuram um tipo de linguagem mais sedutora do que a oferecida por materiais tradicionais da escola, tal como o livro didático.

Neste clima de predileção cognitiva por um formato mais aprazível de conteúdo, vídeos do Youtube emergem em destaque, fator que tem preocupado muito dos professores entrevistados. Isso se deve justamente à falta de garantia de compromisso científico de muitos conteúdos. Se considerarmos a lógica algorítmica do Youtube, ao pesquisar por um tema de história, muitas vezes o estudante pode ser direcionado para canais de youtubers que tratam de temas de história de maneira não científica, partindo de simplificações e generalizações não admitidas pelo debate científico, que é o principal produtor de conhecimento histórico científico. Evidentemente os professores entrevistados demonstraram-se muito preocupados com estas ocorrências, uma vez que, naturalmente, os estudantes atribuem credibilidade ao que assistem no Youtube.

Frente à realidade de ensinar história para uma geração que assiste conteúdos no Youtube, sejam eles vídeo-aulas de conteúdos científicos ou de ideias deturpadas e conspiratórias, a constatação por esta pesquisa é de que os professores entrevistados relataram a procura por aprimoramento, estudo teórico e planejamento de aula para poderem agir de maneira pedagógica na iminência de haver contestações fundamentadas em conteúdos sem embasamento científico. Todos os professores selecionados para a utilização de citações nesta pesquisa, revelaram algum tipo de preparação diante deste cenário. Alguns, inclusive, buscam conhecer os canais tidos como polêmicos, que veiculam interpretações e teorias sem embasamento científico. Nesta perspectiva chegamos na terceira e última unidade de sentido e também no segundo objetivo específico desta pesquisa: descrever as controvérsias que emergem nas práticas docentes de professores de história no ensino médio, provocadas pelo acesso de seus estudantes a conteúdos de história veiculados por youtubers.

Os professores forneceram evidências nesta categoria de análise quanto à preocupação que eles possuem em entender, ou, pelo menos conhecer as ideias e os falseamentos interpretativos que certos youtubers circulam na plataforma. A interação sobre o conhecimento que causa discórdia, exige atitudes pontuais, como por exemplo no caso de Eduardo, que sabendo do teor de possí- veis oposições que podem ocorrer, estuda e busca embasamento teórico, dados e informações para eventualmente poder apresentar em sala de aula. Nesta dinâmica de apresentar aos estudantes dados e interpretações de autores respeitados na produção de conhecimento histórico, o professor media o conhecimento científico com o objetivo de desconstruir a narrativa trazida pelo estudante, tentando estabilizar a controvérsia com a mediação de conceitos. Agindo nesta oportunidade, o professor tem a chance de problematizar a própria origem da informação do estudante, conduzindo-o ao que Schmidt e Cainelli (2004) chamam de "pensar historicamente". Isto é, há nesta oportunidade a chance de levantar problemas e questionamentos, sinalizando ao estudante que o conhecimento histórico científico se constrói justamente pela diversidade de pontos de vista, e mais do que isso, que o conhecimento histórico está em constante construção e depende do debate para que se chegue a um consenso.

Como a recorrência à história como ferramenta de construção de discurso político é uma área que de certa maneira expõe o professor à sorte de intimidações, a maneira encontrada por muitos professores tem sido o que interpretamos como o tipo de "abordagem cognitivista” descrito por Mizukami (1986). Nesta prática, professores têm conseguido construir questões e desafios do pensamento que estimulam a reflexão, conduzindo o educando a desconstrução do conhecimento prévio quando este encontra-se enviesado por discursos distorcidos. Esta prática de lançamento de questões propicia ao estudante a constatação das contradições e fragilidades de sustentação de seus argumentos, uma vez que o conhecimento científico ampara-se nos pilares do método científico, e logo, dispõe de estruturas mais sólidas e amplamente debatidas. Professor Bruno, por exemplo, utiliza esta abordagem para realizar a transposição de conceitos históricos, dando referências confiáveis para que o estudante possa ler com mais facilidade o social.

Por fim, delineou-se por meio da essência das práticas docentes e também por algumas ações dos professores que eles buscam constantemente enaltecer a importância de seu papel como mediador e tradutor de conteúdo em sala de aula. Isso quer dizer que, embora nestes casos elencados o convívio com as redes sociais e o uso das TD seja algo incorporado ao cotidiano da sala de aula, estes actantes não substituem o papel do professor como mediador.

Aludindo ao pensamento de Santaella (2013), concluímos que as práticas docentes buscam, direta ou indiretamente, justamente a complementação entre estes envolvidos na trama social do espaço escolar. Isto é, mesmo quando os conteúdos assistidos no Youtube são 
de origem de vídeo-aulas de qualidade, eventualmente os estudantes buscam a chancela do professor. Salvo a situação relatada por Dante, por exemplo, que diante da confrontação comparativa entre o conteúdo ministrado em sala de aula e o conteúdo assistido pelo Youtube, fez valer em sua avaliação as opções trabalhadas em sala de aula. Isto é, embora o estudante possua um perfil de leitura multimídia e em muitos casos utilize videoaulas do Youtube para estudo antes de uma avaliação, ele há de compreender que as escolhas e recortes teóricos feitos pelo professor em sala de aula são importantes e devem ser complementadas, se desejar, pela leitura de outras mídias, mas nunca, substituídas.

Um dos fatores evidenciados no decorrer da pesquisa é que importante parte do debate político nos últimos anos no Brasil se deu por meio da instrumentalização das redes sociais e pela apropriação de alguns conceitos históricos. Estes conceitos foram esvaziados e articulados para atender a campanha que elegeu a extrema direita no Brasil. Embora nem todos os professores tenham afirmado este contexto explicitamente, isso ficava implícito nas verbalizações, onde era perceptível um tom impregnado pelo sentimento político. Estes componentes não estavam previstos nos objetivos da pesquisa, mas surgem como elementos do contexto de produção desta pesquisa: acirramento das tensões políticas, discursos anticiência, ataque a professores, apropriação de narrativas históricas e, claro, a tentativa de reescrever alguns temas históricos com a finalidade de justificar ocorrências do presente.

\section{REFERÊNCIAS}

Bardin, L. (2004). Análise de conteúdo. Ediçoes 70.

Borges, M. K. (2007). Educação e cibercultura: perspectivas para a emergência de novos paradigmas educacionais. In Vallejo, A. P., \& Zwierewicz, M. (Eds). Sociedade da informação, educação digital e inclusão (pp. 53-86). Insular.

Borges, M. K., \& Oliveira, S. (2016). Virtualização e sociedade digital: reflexões acerca das modificações cognitivas identitárias nos sujeitos imersivos. Conjectura: Filosofia e Educação (UCS), 21(2), 420-440.

Burgess, J, \& Green, J. (2009). YouTube e a revolução digital. Aleph.

Farah, J. (2012). Predicting the Intelligence of Web 3.0 Search Engines. International Journal of Computer Theory and Engineering, 4(3), 443-445. https://doi. org/10.7763/IJCTE.2012.V4.503

Goodman, L. A. (1961). Snowball Sampling. Annals of Mathematical Statistics, 32(1), 148-170. https://doi. org/10.1214/aoms/1177705148
Lapa, A. B., Coelho, I. C., \& Schwertl, S. L. (2015). As redes sociais como um espaço público educacional. 37a Reunião Nacional da Associação Nacional de Pós-Graduação e Pesquisa em Educação (ANPED). Retrieved June $8^{\text {th }}, 2018$, from http://37reuniao. anped.org.br/wp-content/uploads/2015/02/Trabalho-GT16-4529.pdf

Latour, B. (2012). Reagregando o social. Edufba.

Lemos, A. (2008). Cibercultura: tecnologia e vida social na cultura contemporânea. Sulina.

Lemos, A. (2013). A comunicação das coisas: teoria ator-rede e cibercultura. Annablume.

Lévy, P. (2010). Cibercultura. Editora 34.

Mizukami, M. G. N. (1986). Ensino: as abordagens do processo. Editora Pedagogica e Universitaria.

Paletta, F. C., \& Mucheroni, M. L. (2015). Web semântica, agentes inteligentes e a produção de conhecimento na web 3.0. TECSI.

Primo, A. (2007). O aspecto relacional das interações na Web 2.0. Revista da Associação

Nacional dos Programas de Pós-Graduação em Comunicação, 9, 1-21. https://doi.org/10.30962/ec.153

Santaella, L. (2013). Comunicação ubíqua. Repercussões na cultura e na educação. Paulus.

Santaella, L., \& Lemos, R. (2010). Redes sociais digitais: a cognição conectiva do twitter. Paulus.

Schmidt, M. A., \& Cainelli, M. (2004). Ensinar história. Scipione. 